\title{
Evaluation of Resistance of Winter Wheat to Fusarium acuminatum by Inoculation of Seedling Roots with Single, Germinated Macroconidia
}

\author{
M. Mergoum, Former Graduate Student, J. P. Hill, Associate Professor, Department of Bioagricultural Sciences \\ and Pest Management, and J. S. Quick, Professor, Department of Soil and Crop Sciences, Colorado State Univer- \\ sity, Fort Collins 80523
}

\begin{abstract}
Mergoum, M., Hill, J. P., and Quick, J. S. 1998. Evaluation of resistance of winter wheat to Fusarium acuminatum by inoculation of seedling roots with single, germinated macroconidia. Plant Dis. 82:300-302.

Fusarium acuminatum is one of the causal agents of dryland root rot of winter wheat in Colorado. The effect of $F$. acuminatum seedling root infection, recorded at heading, on winter wheat cultivars Sandy and CO84 was investigated in the greenhouse. Winter wheat seeds were surface disinfested, germinated, and vernalized. Vernalized seedling roots were inoculated by placing a single, germinated macroconidium of $F$. acuminatum on the largest root. Inoculated and noninoculated vernalized seedlings were transplanted to pots and half the plants subjected to water stress. Inoculated plants had significantly lower survival rates and, at maturity, lower relative leaf water content, fewer tillers, shorter plant height, and higher cell ion leakage than non-inoculated plants. Wheat cultivars differed significantly for most traits studied. CO84 was susceptible whereas Sandy was more tolerant of the pathogen, particularly under water stress conditions. These results suggest that relative leaf water content, cell ion leakage, and to some extent seedling survival may be useful attributes for evaluation of resistance to the root rot pathogen.
\end{abstract}

Additional keywords: crown rot, foot rot

Common dryland root rot has been reported from most cereal growing areas of the world. However, the occurrence and frequency of causal agents vary from region to region $(4,5,8,10,11,20)$. Cochliobolus sativus (Ito \& Kuribayashi) and several species of Fusarium, including $F$. avenaceaum (Fr.:Fr.) Sacc., F. culmorum (Wm. G. Sm.) Sacc., F. graminearum Schwabe, and $F$. acuminatum Ellis \& Ever., are considered the primary causal agents of root rot of wheat (Triticum aestivum L.; 2,4,15). A complex of $C$. sativus and $F$. acuminatum is mostly responsible for root rot of dryland winter wheat in Colorado and Wyoming (8).

Root rot is a persistent and inconspicuous disease that reduces seedling vigor and impairs the functioning of roots and crowns, resulting in loss of stands, reduced yield, and lower grain quality $(3,11)$. The amount of damage from root rot pathogens varies from year to year and from field to field, depending on the amount of inoculum present as well as the soil and climatic conditions $(1,11,16)$. In addition to envi-

Corresponding author: J. P. Hill

E-mail: jhill@ceres.agsci.colostate.edu

Accepted for publication 1 November 1997.

Publication no. D-1998-0126-01R

(C) 1998 The American Phytopathological Society ronmental factors, certain cultural practices such as early planting $(3,19)$ and high seeding rate may contribute to disease expression $(11,17,20)$.

Previous work, prior to inoculation of roots using 3-week-old winter wheat seedlings that were visually non-contaminated with fungi or bacteria, showed that this procedure could not consistently be used to select genotypes for increased general resistance to $F$. acuminatum (7). However, the data did indicate that comparing plant responses at later stages in the life cycle may increase the effectiveness of the procedure. The major objective of this work was to evaluate the effect of seedling root inoculation with a single, germinated macroconidium on plants of two visually noncontaminated winter wheat cultivars on several agronomic and physiologic characters at heading in the greenhouse.

\section{MATERIALS AND METHODS}

The $F$. acuminatum isolate used in this study was originally obtained from a winter wheat plant collected from a commercial Colorado wheat field and single-spore cultured in petri dishes containing potato dextrose agar (PDA). Several other $F$. acuminatum isolates were tested and found to be equally virulent under similar experimental conditions.

The $F$. acuminatum isolate was cultured in petri dishes containing several 10- to 15 $\mathrm{mm}$ sections of autoclaved carnation leaves on the surface of $1.5 \%$ water agar (WA) to induce production of macroconidia. After incubation for 6 days on a laboratory bench at room temperature $\left(20\right.$ to $\left.23^{\circ} \mathrm{C}\right)$, a 15 $\mathrm{mm}$ section of colonized carnation leaf was placed in a test tube containing $10 \mathrm{ml}$ of autoclaved distilled water and shaken to remove the macroconidia. The spore suspension was diluted several times with autoclaved distilled water to produce several different concentrations. The conidial concentrations were serially diluted (1:10) three times to provide various numbers of spores on the agar to insure a spacing was achieved so individual germinated macroconidia could be isolated. Two $\mathrm{ml}$ of the suspension were placed in a petri dish containing $1.5 \%$ WA. Excess water was removed $5 \mathrm{~min}$ later, and the dishes were stored at room temperature in the laboratory. After $24 \mathrm{~h}$, single, germinated macroconidia were aseptically excised with a small section of water agar, and used to inoculate the seedling roots.

Winter wheat seeds were surface disinfested by immersion in a sequential series of solutions containing $70 \%$ ethanol, $20 \%$ $\mathrm{NaOCl}, 0.15 \% \mathrm{HgCl}_{2}$, and autoclaved distilled water $(6,7)$. Disinfested seed were placed in petri dishes ( 3 to 5 seeds per petri dish) containing PDA and stored in the dark at room temperature. After 5 days, visually non-contaminated seedlings were aseptically transferred to test tube slants containing WA and vernalized by placing them in the dark at $1^{\circ} \mathrm{C}$ for 6 to 8 weeks.

Plants were inoculated by placing a single, germinated macroconidium, with a small section of WA, on the largest root of each vernalized seedling. After 4 days, an equal number of inoculated and non-inoculated seedlings were removed from the test tubes and transplanted to $15-$ by $20-\mathrm{cm}$ pots ( 3 plants per pot) containing a mixture of Weld silt loam soil, peat, and vermiculite $(2: 2: 1, \mathrm{vol} / \mathrm{vol} / \mathrm{vol})$ that had been treated with aerated steam for 0.5 hours Five pots of each treatment were then transferred to a greenhouse bench with no supplemental lighting.

Greenhouse experiments were conducted on two winter wheat cultivars, Sandy and CO84, previously rated in the field as resistant and susceptible, respectively, to dryland root rot complex pathogens in Colorado (J. S. Quick, unpublished data; 7). Treatments included waterstressed and non-stressed plants with seed- 
ling roots inoculated with a single, germinated macroconidia of $F$. acuminatum, and non-inoculated controls. Plants were moisture-stressed by withholding water until wilting started (approximately -15 bars, $10 \%$ soil moisture) at which time water was added to bring the soil up to field capacity. Non-stressed plants were watered daily to maintain the soil approximately at field capacity (approximately $-1 / 3$ bar). Percent moisture levels and approximate water amounts were initially established by weight.

Treatments were arranged in a split-split plot design with 15 replications. Each replication consisted of one plant. Cultivars were the main plots, water stress the subplots, and seedling root inoculation the sub-sub plots.

Percent seedling survival was recorded 1 week after transplanting. Plant height, relative water content, ion leakage, and disease assessment were recorded at heading (Feekes 10.1 to 10.5). Percent infection was determined by examining washed subcrown internodes for symptoms. The fungus was easily isolated from lesions. The fungus was not isolated from subcrown internodes that appeared healthy.

Relative water content of flag leaves was determined by weighing the excised leaves immediately after removal from the plant. The leaves were immersed in test tubes containing $50 \mathrm{ml}$ distilled water. After $24 \mathrm{~h}$, the leaves were weighed, placed in small paper bags, dried at $60^{\circ} \mathrm{C}$ for $24 \mathrm{~h}$, and reweighed. Relative water content (RWC) of the flag leaf was calculated according the following equation: RWC $(\%)=[(\mathrm{FW})-(\mathrm{DW})] /[(\mathrm{TW})-$ $(\mathrm{DW})] \times 100 . \mathrm{FW}, \mathrm{DW}$, and TW are the fresh weight, dry weight, and turgid weight, respectively, of the individual flag leaves.

Ion leakage was estimated by measuring the electric conductivity, using a "conductivity bridge" (Conductivity Bridge, Model PM-70CB, SYBRON/Barnstead), of the distilled water solution in which the flag leaves had been suspended for $24 \mathrm{~h}$.

The experiment was repeated once. After determining there were no significant differences in the variances of any of the recorded traits between experiments, the data from the two experiments were pooled.

In a separate experiment, the number of live inoculated and non-inoculated vernalized seedlings was recorded 1 week after transplanting into pots and subsequent transfer to a greenhouse bench. The experiment was repeated once and consisted of 45 seedlings for each treatment.

In a different type of water stress experiment, all root-inoculated and non-inoculated Sandy and CO84 plants were watered daily until heading (Feekes 10.1 to 10.5), at which time watering was discontinued. Flag leaves from 15 plants of each treatment were collected 3, 6, 9, 12 , and 15 days after watering was stopped. RWC and electric conductivity were determined. The pots were arranged in a completely random design in the greenhouse and the experiment was repeated once. The RWC and electrical conductivity data from the two experiments were pooled and analyzed.

\section{RESULTS}

Seedling root inoculation of visually non-contaminated seedlings with a single, germinated macroconidium of $F$. acuminatum significantly reduced survival of C084 plants from 74 to $35 \%$. Seedling percent survival of Sandy, however, was not significantly affected by inoculation. Seedling survival varied from 70 to $75 \%$ for both inoculated and non-inoculated plants.

Percent plant infection was significantly increased in the water-stressed plants. Under full irrigation, $56 \%$ of the inoculated Sandy plants and $73 \%$ of the CO84 plants were infected. Under water stress, percent infected plants significantly $(P<5 \%)$ increased to $83 \%$ for Sandy and $97 \%$ for CO84. The percent infection of $\mathrm{CO} 84$ plants was significantly greater than for Sandy plants under both water regimes.

Seedling root inoculation with a single germinated macroconidium of $F$. acuminatum significantly reduced average number of tillers and their height for plants of

Table 2. Average $\mathrm{e}^{\mathrm{a}}$ effects of water stress and seedling root inoculation with a single, germinated macroconidium of Fusarium acuminatum on relative water content (RWC) and electric conductivity (EC) of the flag leaves of the hard red winter wheat cultivars Sandy and CO84, 3 to 15 days after watering (DAW) at Feekes 6

\begin{tabular}{lcccccc}
\hline & & \multicolumn{2}{c}{$\mathbf{R W C}(\boldsymbol{\%})^{\mathbf{b}}$} & & \multicolumn{2}{c}{$\mathbf{E C}(\boldsymbol{\mu} \mathbf{S})^{\mathbf{b}}$} \\
\cline { 3 - 4 } \cline { 6 - 7 } DAW & Inoculated & Sandy & $\mathbf{C O 8 4}$ & & Sandy & CO84 \\
\hline 3 & + & 75 & 68 & & 0.97 & 1.11 \\
& - & 83 & 79 & & 0.95 & 1.01 \\
6 & + & 65 & 51 & & 1.18 & 1.44 \\
& - & 78 & 76 & & 1.14 & 1.18 \\
9 & + & 43 & 26 & & 1.14 & 2.89 \\
& - & 56 & 47 & & 1.23 & 1.24 \\
12 & + & 33 & 23 & & 1.54 & 3.96 \\
& - & 41 & 34 & & 1.43 & 1.53 \\
15 & + & 31 & 21 & & 1.64 & 3.90 \\
& - & 40 & 33 & & 1.65 & 1.75 \\
\hline
\end{tabular}

a Average of 30 flag leaves from two experiments (15 leaves each).

${ }^{\mathrm{b}}$ Least significant differences at 0.05 level are 6 and 0.54 for comparing any RWC or EC means, respectively.

Table 1. Average a plant height (PH), tiller number (TN), relative water content (RWC), and electric conductivity (EC) at boot stage (Feekes 10) of nonstressed (NS) or water-stressed (WS) Sandy and CO82 hard red winter wheat plants non-inoculated (NI)or seedling root-inoculated (SRI) with a single, germinated macroconidium of Fusarium acuminatum

\begin{tabular}{|c|c|c|c|c|c|c|c|}
\hline \multirow[b]{2}{*}{ Trait } & \multirow[b]{2}{*}{ Inoculation } & \multicolumn{3}{|c|}{ Sandy } & \multicolumn{3}{|c|}{$\mathrm{CO84}$} \\
\hline & & NS & WS & $\mathbf{L S D}^{\mathbf{b}}$ & NS & WS & LSD \\
\hline \multirow{3}{*}{$\mathrm{PH}(\mathrm{m})$} & SRI & 0.60 & 0.43 & 0.07 & 0.62 & 0.39 & 0.07 \\
\hline & NI & 0.65 & 0.47 & 0.07 & 0.66 & 0.45 & 0.07 \\
\hline & $\operatorname{LSD}^{\mathrm{c}}$ & 0.03 & 0.03 & & 0.03 & 0.03 & \\
\hline \multirow[t]{3}{*}{$\mathrm{TN}$ (per plant) } & SRI & 3.90 & 3.70 & 0.20 & 2.90 & 1.90 & 0.20 \\
\hline & NI & 4.20 & 4.40 & 0.20 & 3.90 & 3.40 & 0.20 \\
\hline & LSD & 0.40 & 0.40 & & 0.40 & 0.40 & \\
\hline \multirow[t]{3}{*}{ RWC (\%) } & SRI & 52.00 & 44.00 & 6.00 & 41.00 & 29.00 & 6.00 \\
\hline & NI & 60.00 & 55.00 & 6.00 & 53.00 & 50.00 & 6.00 \\
\hline & LSD & 4.00 & 4.00 & & 4.00 & 4.00 & \\
\hline \multirow{3}{*}{$\mathrm{EC}(\mu \mathrm{S})$} & SRI & 1.57 & 2.84 & 0.35 & 1.67 & 3.24 & 0.35 \\
\hline & NI & 0.98 & 1.14 & 0.35 & 1.32 & 1.32 & 0.35 \\
\hline & LSD & 0.30 & 0.30 & & 0.30 & 0.30 & \\
\hline
\end{tabular}

${ }^{a}$ Average of 30 plants or flag leaves from two experiments (15 plants each).

${ }^{\mathrm{b}}$ Least significant difference (LSD) at 0.05 level within rows.

${ }^{\mathrm{c}}$ LSD at 0.05 level within columns. 
both cultivars under both water-stress and non-water-stress conditions (Table 1). Similarly, root inoculation and water stress resulted in reduced plant height under both soil moisture regimes.

The relative water content of Sandy and C084 flag leaves were significantly reduced by root infection with $F$. acuminatum under no-water-stress as well as under water-stress conditions (Table 1). CO84 flag leaves were more affected by root inoculation with $F$. acuminatum than Sandy flag leaves when grown under water stress (Table 1).

Electrical conductivity is proportional to the number of free ions in the solution and generally indicates the amount of cell injury caused by stress (14). Cultivars, water stress, and inoculation significantly affected electrical conductivity of flag leaf solutions (Table 1). Under no water stress, the solution electrical conductivity from both Sandy and CO84 flag leaves were significantly increased by root inoculation. Non-inoculated plants grown under continuous water stress had significantly greater flag leaf electrical conductivity than non-stressed plants. Root inoculation resulted in another significant increase in flag leaf electrical conductivity of the plants already stressed by the low water regime.

In the second water stress experiment (Table 2), the flag leaf relative water content of both cultivars decreased significantly with the severity of water stress up to 9 days after the last irrigation. The severity of reductions in RWC of CO84 flag leaves due to inoculation increased as the time from the last irrigation increased. For 12 and 15 days after the last irrigation, the flag leaf RWC reductions due to inoculation were less marked and comparable to the low level water stress reductions. The RWC reductions of Sandy were less than those of CO84. The flag leaf RWC of inoculated CO84 plants was significantly less than that of Sandy plants under all water stress levels (Table 2).

Under increasing water stress over time in the second experiment, significant differences between the two cultivars were observed for flag leaf electrical conductivity due to root inoculation treatments (Table 2). Under mild water stress (3 and 6 days after the final irrigation), seedling root inoculation did not significantly affect the flag leaf electrical conductivity of either cultivar. Under greater water stress $(9,12$, and 15 days after watering was discontinued), significant differences in flag leaf electrical conductivity occurred only between inoculated and non-inoculated $\mathrm{CO} 84$ plants.

\section{DISCUSSION}

Seedling root inoculation of wheat cultivars Sandy and CO84 with single, germi- nated macroconidia of $F$. acuminatum did not produce classic white heads symptoms of root rot under any water stress regime in the greenhouse. However, seedling root inoculation significantly reduced seedling survival, tiller number, plant height, and RWC of flag leaves, and increased ion leakage of both cultivars. In general, water stress enhanced the effects of seedling root inoculation on most of the measured characteristics, especially on CO84 plants. CO84 seedlings were more affected than Sandy seedlings by $F$. acuminatum root inoculation alone or combined with water stress. The data on percent seedling survival and plant infection at heading suggest that Sandy is more resistant than CO84 to F. acuminatum.

The significant reduction in average tiller number after seedling root inoculation is supported by several workers $(9,12,13,18)$ who reported fewer tillers per plant due to root rot in the Prairie Provinces of Canada.

Infection by $F$. acuminatum apparently caused more ion leakage in the flag leaves due to water stress for CO84 than for Sandy. It is not known if the increased ion leakage is due to cell injury directly by the fungus or the physiological effects of increased water stress due to the disease. This reduced ion leakage may indicate another aspect of resistance of cultivar Sandy to the root rot pathogens.

The work reported here confirms our previous field observations that Sandy is more resistant to the root rot pathogens than CO84. These results indicate that percent plant survival, average tiller number, average plant height, reduced water content, and electrical conductivity after root inoculation of visually non-contaminated seedlings, especially under water stress, may be useful in initial screening of winter wheat for resistance to root rot disease. Those that show potential resistance could then be advanced in the breeding program. Plant survival is especially interesting because of the shorter experimental time involved. However, vernalization and seed disinfestation are somewhat timeconsuming. More research is needed to try to develop a relatively rapid, efficient method of identifying winter wheat genotypes resistant to root rot pathogens of winter wheat.

\section{LITERATURE CITED}

1. Broscious, S. C., and Frank, J. A. 1986. Effects of crop management practices on common root rot of winter wheat. Plant Dis. 70:857-859.

2. Burgess, L. W., Wearing, A. H., and Toussoun, T. A. 1975. Survey of Fusaria associated with crown rot of wheat in eastern Australia. Aust. J. Agric. Res. 26:791-799.

3. Fenster, C. R., Boosalis, M. G., and Weihing, J. L. 1972. Date of planting studies of winter wheat and winter barley in relation to root and crown rot, grain yields and quality. Nebr. Agric. Exp. Res. Bull. 250

4. Fernandez, J. A., Wofford, D. S., and Horton, J. L. 1985. Interactive effects of freezing and common root rot fungi on winter wheat. Phytopathology. 75:845-847.

5. Grey, W. E., Engel, R. E., and Mathre, D. E. 1991. Reaction of spring barley to common root rot under several moisture regimes: Effect on yield components, plant stand, and disease severity. Can. J. Plant Sci. 71:461472.

6. Hill, J. P., Armitage, C. R., Kautzman-Eades, D., and Hanchey, P. 1987. Surface disinfestation of wheat seed and inoculation of seedling roots with single macroconidia of Fusarium acuminatum. Plant Dis. 71:130-131.

7. Hill, J. P., and Blunt, D. L. 1994. Wheat seedling response to root infection by Cochliobolus sativus and Fusarium acuminatum. Plant Dis. 78:1150-1152.

8. Hill, J. P., and Fernandez, J. A. 1983. Fungi associated with common root rot of winter wheat in Colorado and Wyoming. Plant Dis. 67:795-796.

9. Ledingham, R. J., Atkinson, T. G., Horricks, J. S., Mills, J. T., Piening, L. J., and Tinline, R. D. 1973. Wheat losses due to common root rot in the prairie provinces of Canada, 196971. Can. Plant Dis. Surv. 53:113-122.

10. Lyamani, A. 1988. Wheat root rot in West Central Morocco and effects of Fusarium culmorum and Helminthosporium sativum seed and soil-borne inoculum on root rot development, plant emergence, and crop yield Ph.D. thesis. Iowa State University, Ames.

11. Mergoum, M. 1991. Effects of Fusarium acuminatum, Fusarium culmorum, or Cochliobolus sativus on Wheat. Ph.D. diss. Colorado State University, Fort Collins.

12. Piening, L. J. 1973. Differential yield response of 10 barley cultivars to common root rot. Can. J. Plant Sci. 53:763-764.

13. Piening, L. J., Atkinson, T. G., Horricks, J. S., Ledingham, R. J., Mills, J. T., and Tinline, R. D. 1976. Barley losses due to common root rot in the prairie provinces of Canada, 19701972. Can. Plant Dis. Surv. 56:41-45.

14. Shanahan, J. F., Edwards, I, B., Quick, J. S, and Fenwick, R. J. 1990. Membrane thermostability and heat tolerance of spring wheat Crop Sci. 30:247-251.

15. Specht, L. D., and Rush, C. M. 1988. Fungi associated with root and foot rot of winter wheat and populations of Bipolaris sorokiniana in the Texas panhandle. Plant Dis. 72:959-963.

16. Statler, G. D., and Darlington, L. C. 1972 Resistance of hard red spring wheat and durum wheat to seedling blight and crown rot. Plant Dis. Rep. 56(9): 788-792.

17. Tinline, R. D. 1986. Agronomic practices and common root rot in spring wheat: Effect of depth and density of seedling disease. Can. J. Plant Pathol. 5:174-176.

18. Verma, P. R., Morrall, R. A. A., and Tinline, R. D. 1976. The effect of common root rot on components of grain yield in Manitou wheat Can. J. Bot. 54:2888-2892.

19. Watkins, J. E., Boosalis, M. G., and Kerr, E. D. 1980. Root and crown rot of winter wheat Inst. Agric. Nat. Resour. Coop. Ext. Serv., NebGuide G80-483, University of Nebraska, Lincoln.

20. Wildermuth, G. B., and McNamara, R. B 1991. Effects of cropping history on soil populations of Bipolaris sorokiniana and common root rot of wheat. Aust. J. Agric. Res. 41:1-10. 